\title{
Vacina, antivacinismo e biopoder: a história e os estratos do tempo
}

BAHIA LOPES, Myriam.

Corpos Inscritos: vacina e biopoder, Londres e Rio de Janeiro, 1840 e 1904.

$\left.\right|^{1}$ Luiz Alves Araújo Neto |

1 Fundação Oswaldo Cruz. Rio de Janeiro-RJ. Brasil (luizalvesan@hotmail.com). ORCID: 0000-0001-7965-2957

Recebido em: 23/05/2021

Aprovado em: 03/06/2021

Revisado em: 17/10/2021

DOI: http://dx.doi.org/10.1590/S0103-73312021310425

Um dos movimentos analíticos fundamentais da História consiste no que Michel de Certeau chamou de relação entre o "presente historiográfico" e o "passado histórico" (Certeau, 2011: 163-178). Em suma, a historiografia mobiliza questôes, interesses, preocupaçóes e perspectivas de seu presente para formular perguntas ao passado. Nessa diacronia, a disciplina histórica sempre fornece interpretaçóes acerca de fenômenos pretéritos que dizem tanto sobre o tempo de produção da pesquisa quanto acerca do tempo pesquisado. $\mathrm{O}$ processo analítico ganha ainda mais complexidade quando, no complexo percurso entre o passado investigado e a publicação/divulgação do texto historiográfico, estão envolvidas diferentes temporalidades.

Este é o caso do livro Corpos Inscritos: vacina e biopoder, Londres e Rio de Janeiro, 1840 e 1904, fruto da tese de doutorado de Myriam Bahia Lopes. A tese, defendida em 1997 na Université Paris Diderot, sob orientação de Michelle Perrot, foi traduzida e transformada em livro em 2020, com publicação pelo Núcleo de Estudos da História da Ciência e da Técnica (NEHCIT) da UFMG. Explorando um tópico bastante atual para nós, em 2021, a participação dos movimentos 
antivacinistas no desenvolvimento da vacina antivariólica e na prática da vacinação, Bahia Lopes propóe "reconhecer um estilo de luta próprio das sociedades disciplinares" (Bahia Lopes, 2020: 66).

Para tanto, a autora transita entre diferentes séries documentais - de publicaçôes médicas a charges em jornais - e abordagens historiográficas (privilegiando questôes da história urbana e da história social). Confrontando o que demarca como uma historiografia da varíola, da vacina e da Revolta da Vacina, Bahia Lopes afirma que deseja "extrair da história da vacinação antivariólica o papel fundamental que os antivacinadores exercem ao apontar os limites da inovação técnica" (Bahia Lopes, 2020: 179). Sua análise tem recortes espaciais fluidos, mas dá ênfase à experiência londrina no século XIX e à do Rio de Janeiro na virada para o século XX.

Dada à natureza polêmica do tema abordado em Corpos Inscritos, um comentário inicial é fundamental: embora elabore uma narrativa bastante crítica à história da medicina e à construçáo do que chama frequentemente de "monumento da vacina”, Myriam Bahia Lopes não assume uma postura negacionista à vacinação como estratégia de prevenção. Sua análise se aproxima de perspectivas relevantes na historiografia do século XX, como a "história vista de baixo" (Krantz, 1990), de forte inspiração marxista e a história cultural ou história social da cultura. Nesse sentido, a autora traça uma narrativa que associa a medicina ao poder estatal e corporativo, enquanto caracteriza os antivacinistas entre a multidão e os grupos dissonantes, ambos apagados pela monumentalizaçáo (Runia, 2015) da vacina.

Para fins de organização desta resenha, dividirei a discussão em tópicos. Primeiramente, apresentarei aspectos formais do livro, a estrutura dos capítulos, seus argumentos principais e críticas à historiografia. Em seguida, irei me deter em como a leitura do livro envolve a compreensão de temporalidades distintas: a criação da vacina por Edward Jenner; a incorporação da vacinação como estratégia por autoridades públicas municipais; as resistências e transformaçôes na vacina antivariólica no final do século XIX e início do XX; o desenvolvimento da pesquisa e escrita da tese de Bahia Lopes; e a publicação de seu livro, em 2020. Por fim, discutirei pontos específicos levantados pela autora ao longo da obra e que têm ressonância em produçóes dos campos da História das Ciências, Estudos Sociais das Ciências e História da Medicina, especificamente: as simetrias e assimetrias no desenvolvimento de conhecimentos e técnicas; os regimes de objetividade na ciência e na medicina; e a relação entre vacina e vacinação. 


\section{O percurso do livro}

Corpos Inscritos possui cinco capítulos, divididos a partir do critério temático, mas que se conectam através dos argumentos da autora e de retomadas na análise de fontes específicas. No capítulo introdutório, "(Des)crever e (Ins)crever a vacinação global", Bahia Lopes aponta que "não seguimos uma ordem cronológica no texto" (Bahia Lopes, 2020: 31), explicitando uma opçáo narrativa inspirada nos trabalhos de Michel Foucault, tomando como pontos de referência e inflexão na história da vacinação antivariólica as rupturas e descontinuidades. Antes do primeiro capítulo, três breves apresentaçóes, respectivamente de Michelle Perrot, Maria Stella Bresciani e da autora, situam a publicação do livro. Nos dois primeiros textos, é destacado certo caráter pioneiro da pesquisa em questáo, sobretudo por colocar em evidência, na leitura de Perrot e Bresciani, a atuação de grupos até então vistos como monolíticos, ignorantes e marginais pela história da medicina.

Alguns pontos do capítulo introdutório merecem atenção especial, devido ao seu caráter estruturante no livro de Bahia Lopes. Por exemplo, a autora destaca a importância das zonas portuárias de Londres e do Rio de Janeiro para a demarcação do seu estudo, principalmente pela demanda por medidas sanitárias nessas regiôes e pelo vetor de urbanizaçáo, fortemente associado às ideias de civilização e progresso pontos caros à crítica de Lopes. A partir da noção de heterotopia de Michel Foucault, defende que o porto "é um espaço limite, ao mesmo tempo ponto de chegada e partida, barreira e passagem” (Bahia Lopes, 2020: 42-43). Ainda, são associados ao porto aspectos importantes, como o papel da higiene nas relaçóes diplomáticas (Ibidem: 46) e da prevenção na remodelação urbana (Ibidem: 45).

No segundo capítulo, "A caricatura e a medicina uma estética da violência", a autora realiza uma discussão bastante cara à história cultural e à história social, abordando as representaçôes de figuras de poder, como Oswaldo Cruz, em charges publicadas no Rio de Janeiro e em Londres. Através de uma reflexão sobre como a ridicularização de figuras públicas mobiliza signos de resistência a processos considerados opressivos, a autora traça uma narrativa quase a contrapelo da história da vacinação antivariólica (fazendo coro à citação de Benjamin que serve epígrafe ao livro). Segundo Bahia Lopes, a importância do estudo das caricaturas repousa, sobretudo, no amplo alcance desse tipo de comunicação (Bahia Lopes, 2020: 93) e na oferta de "um verdadeiro catálogo político ilustrado" (Ibidem: 102). 
Alguns aspectos do segundo capítulo são relativamente polêmicos e serão apontados mais adiante. No que tange ao aspecto formal da apresentaçáo da obra, vale o registro de que duas passagens entre as páginas 110 e 111, acerca da falocracia na representação feminina e da lanceta, são repetidas de forma literal. Da mesma forma, o último parágrafo da página 107 é composto por dois períodos repetidos.

O terceiro capítulo, "A formação da opiniāo pública", talvez possa ser considerado o coração do trabalho, pois traz de forma mais explícita os tensionamentos e confrontos discutidos pela autora. Partindo de uma leitura crítica feita por um imunologista sobre a vacina como fundadora da imunologia, Lopes discute a produção do “acontecimento vacina antivariólica" (Bahia Lopes, 2020: 137). Nesse capítulo, um interessante movimento analítico e narrativo coloca lado a lado o desenvolvimento da vacina como instrumento e fato científico e a formulação de denominaçóes simplificadoras aos antivacinistas, caso de vacinófobo. Com uma análise bastante interessante sobre a relação entre as palavras e as coisas, Lopes aponta o poder das denominações na marginalização dos movimentos antivacinistas, considerados "o monumento da burrice humana” (Ibidem: 148) por contemporâneos e historiadores, caso de Pierre Darmon. A questão central de Lopes, ao pensar a historiografia (em um sentido bastante amplo), é que "médicos e políticos exageram e distorcem os gestos de resistência da população" (Ibidem: 150), o que possui grande ressonância nas narrativas históricas.

O capítulo IV, “A prevenção da varíola: semelhanças e divergências", é dedicado à história das práticas médicas de prevenção à varíola e à participação dos movimentos antivacinistas no seu desenvolvimento e estabelecimento. Nesse ponto, Bahia Lopes realiza uma discussão que foi ampliada e aprofundada pela história da medicina e pelos Estudos Sociais das Ciências nas últimas duas décadas, acerca da padronização de procedimentos, nomenclaturas e protocolos para a prática médica. No esforço de realizar um contraponto à narrativa que monumentaliza a inovação técnica como signo de progresso e civilização (Bahia Lopes, 2020: 193), a autora enfatiza os limites da vacina como instrumento de prevenção - destacando também o argumento dos antivacinistas de que o isolamento poderia ser uma medida tão eficaz quanto a vacina. No limite, Lopes defende que a história da vacina antivariólica "demonstra uma enorme dificuldade por parte de seus agentes em compreender a complexidade do percurso que vai do laboratório até a sociedade" (Ibidem: 205). Ainda, segundo a autora, apesar da negação das controvérsias e das resistências pelos cientistas (Ibidem: 
230), os movimentos antivacina teriam operado nessas brechas das limitaçôes e contradiçóes da vacina para mobilizar suas pautas de resistência.

Finalmente, o último capítulo, "O encontro de lutas diversas", mostra a aproximação entre os movimentos antivacina e outras pautas de resistência social, como os movimentos de mulheres e a homeopatia. Nesse capítulo, Bahia Lopes ressalta a associaçáo entre medicina e biopoder, colocando as lutas dos antivacinistas no espectro do que Michel de Certeau (2012) chama de "redes de antidisciplina" do cotidiano, elaboradoras de táticas de subversão do poder. Ainda, à guisa de conclusão, Bahia retoma seu ponto de partida de crítica ao monumento vacina, também reafirmando o valor estratégico da medida preventiva (Bahia Lopes, 2020: 254), e reforça sua demanda por uma leitura da história da medicina questionadora de seus limites e vinculaçóes ao biopoder.

\section{Os vários tempos de um texto}

O historiador alemão Reinhart Koselleck, nome referencial da história dos conceitos e importante teórico da disciplina, defendeu, na década de 1970, que a experiência histórica é definida pela relação entre "espaços de experiência" e "horizontes de expectativa” (Koselleck, 2006:309-313). Resumindo grosseiramente, essas categorias se referem ao movimento temporal de olhar para o(s) futuro(s) a partir de um conjunto de experiências acerca do passado. Para Koselleck, os historiadores não podem se furtar a essa dimensão de temporalização da vivência histórica para construir suas análises. É nesse sentido que considero importante a percepção dos diferentes "estratos de tempo" (Koselleck, 2014) presentes no livro de Myriam Bahia Lopes.

Publicado em 2020, Corpos Inscritos encontra um cenário de profundos debates acerca dos negacionismos científicos e da confiança na ciência (Oreskes, 2019). No caso brasileiro, esses temas tornam-se ainda mais acalorados por lidarmos com uma resposta governamental caótica à pandemia de Covid-19, movida principalmente por posiçôes de negação ao empreendimento científico, às recomendações de instituições sanitárias e à importância da vacinação como medida preventiva. Assim, o presente de publicação da pesquisa de Bahia Lopes envolve um olhar bastante crítico aos movimentos antivacinistas, aos quais se atribui uma queda vertiginosa na adesão à vacinação e o retorno de doenças consideradas erradicadas ou controladas, como o sarampo. Essa atmosfera pode causar resistência de leitores e leitoras aos argumentos 
centrais mobilizados pela autora, que constrói uma narrativa com teor de denúncia ao poder do Estado e da corporação médica.

Entretanto, é necessário estar atento ao presente de produção da tese de Myriam Bahia Lopes, as décadas de 1980 e 1990 e os debates sobre reformas e revoltas urbanas no Rio de Janeiro. Nesse período, autores como Jaime Benchimol (1990), Tânia Maria Fernandes (1991) José Murilo de Carvalho (1987), Nicolau Sevcenko (1984) e Sidney Chalhoub (1996) publicaram trabalhos que buscaram explicar, por diferentes vieses, o fenômeno social conhecido como Revolta da Vacina. Compartilhando os referenciais da história urbana, esses autores pensaram a revolta como um evento ligado à cidade do Rio de Janeiro, considerada por eles um sujeito histórico. Ao esquadrinhar Londres e Rio como seus espaços de análise, Bahia Lopes está se dirigindo a essa historiografia e aos debates sobre o papel das multidóes na história, não ao tema dos negacionismos científicos.

Certamente, seria útil uma melhor contextualização dessas temporalidades pela própria autora em seu livro, a fim de situar o leitor quanto aos seus diálogos e debates ao lidar com o movimento antivacina. Levando em conta a força do tema, é razoável pensar que o público do livro seja mais de pessoas interessadas nas pautas da vacina e dos negacionismos do que estudiosos da história urbana.

No espectro do presente da pesquisa, o leitor de Corpos Inscritos encontrará provocaçôes de Bahia Lopes à historiografia dos anos 1980 e 1990, a exemplo da forte crítica ao livro Cidade Febril, de Sidney Chalhoub, ao qual ela imputa uma "obsessão por encontrar indícios da resistência dos negros" que o teria levado a uma "explicação inverossímil” para a revolta (Bahia Lopes, 2020: 36). A relação com o espaço de experiência da pesquisa também motiva uma leitura bastante crítica à figura de Oswaldo Cruz, representação principal do biopoder exercido pela medicina no Rio de Janeiro, segundo a autora.

Apesar desses confrontos serem estruturantes da obra de Bahia Lopes, existem outros tópicos bastante instigantes relacionados às temporalidades analisadas pela autora. Embora não adote referenciais metodológicos e teóricos da história da medicina ou da história das ciências para construir sua análise, Myriam Bahia Lopes direciona várias críticas a esses campos, principalmente quanto à construção narrativa do "monumento da vacina” pelo que denomina de historiografia da varíola e da vacina.

Por exemplo, a autora alega que "a história das ciências por ser normativa julga o passado com as aquisiçôes da ciência atual” (Bahia Lopes, 2020: 138). Essa 
afirmação é, no mínimo, curiosa, levando em conta as citaçôes pontuais a Bruno Latour e a Ludwik Fleck (ainda que esse de forma indireta), autores que têm entre suas contribuiçôes para o campo historiográfico a percepção da historicidade da história das ciências. Mostra, também, uma visão bastante restritiva do que seria uma historiografia das ciências, associada aos cientistas que elaboram narrativas acerca do passado de suas disciplinas e a historiadores aproximados da vertente positivista. Conforme sugerem Huisman e Warner (2006: 5), é preciso diferenciar as várias historiografias da medicina, desde o que poderia ser chamado de uma perspectiva mais tradicional de uma "história médica", até as variadas perspectivas desenvolvidas por historiadores e historiadoras profissionais.

Em suma, o livro aborda três diferentes temporalidades em sua análise empírica. O período de invenção e estabilização da vacina antivariólica por Edward Jenner abarca o final do século XVIII e as primeiras décadas do XIX, envolvendo disputas sobre a prioridade da descoberta e a eficácia do procedimento (Bahia Lopes, 2020: 159-160). Entre os anos 1830 e os anos 1870 (década demarcada pela autora como o surgimento da imprensa antivacinista), tem-se a transformação da vacinação em estratégia por médicos e gabinetes de saúde pública, ainda que com limitações em sua aplicação em diferentes contextos, caso da comparação entre Londres e Rio de Janeiro. Finalmente, o período de virada do século XIX para o XX, um terceiro momento de análise do livro, corresponde à emergência da microbiologia, ao fortalecimento dos movimentos antivacinistas e à própria revolta no Rio de Janeiro.

É importante delimitar que a vacina antivariólica, entendida aqui como um instrumento biomédico (Clarke; Fujimura, 1992), sofreu transformaçôes em todos esses períodos, sendo difícil, inclusive, considerá-la a mesma entidade em todo esse percurso de mais de um século. A historicidade da vacina é fundamental para o argumento de Bahia Lopes, uma vez que a autora sustenta ao longo do livro o papel dos antivacinistas nessas reformulaçóes do instrumento. Entretanto, também expóe aspectos que merecem maior discussão, como a caracterização de um "acontecimento vacina antivariólica", diretamente ligado a percepçóes de uma "história universal da vacinação antivariólica" (Bahia Lopes, 2020: 54).

\section{Vacina(ção), simetria e objetividade médica}

Longe de pretender dar conta da longa discussáo sobre a história da vacina e da vacinação antivariólica, tampouco das formas de resistência cotidiana aos dispositivos 
disciplinares do biopoder, considero relevante destacar três aspectos discutidos com frequência no livro Corpos Inscritos. Essas observações, é preciso situar, se referem à história das ciências e da medicina e aos estudos sociais das ciências.

De saída, a autora propóe uma abordagem que coloca "a verdade da vacina antivariólica entre parênteses", estudando "seu longo processo de produção" (Bahia Lopes, 2020: 60). A preocupação de Myriam Bahia Lopes diz respeito à relação assimétrica traçada por uma narrativa histórica que tome em consideração somente o sucesso da vacina e da vacinação, ou, como coloca Latour (2000), uma análise sobre a ciência após o fechamento de suas caixas-pretas. Nesse sentido, o estudo de Bahia Lopes mobiliza o que David Bloor (2009:54) identificou como princípio da simetria, ou seja, uma observação dos enunciados em disputa que leve em conta seu contexto de formulação, não seu resultado. O principal exemplo historiográfico de aplicação dessa abordagem é o clássico livro de Steven Shapin e Simon Schaffer (2011), os quais estudam a controvérsia entre Thomas Hobbes e Robert Boyle acerca da existência ou não do vácuo.

$\mathrm{Na}$ trilha de uma abordagem simétrica entre os defensores e os críticos da vacina, porém, Bahia Lopes parece diminuir outras assimetrias necessárias à compreensão das disputas envolvendo o instrumento vacina. Em sua representação dos movimentos antivacina, por exemplo, parece haver poucas disputas entre os atores e instituiçóes, formando quase grupos homogêneos em seus posicionamentos e mobilizaçôes. Em contrapartida, o empreendimento científico é mostrado como algo conflituoso e, em certa medida, bagunçado - o que, como alega John Law ${ }^{1}$, é uma imagem correta. Essa homogeneização serve como espelho à simplificação feita pelos defensores da vacina ao taxar os críticos de vacinófobos, deixando ausente as nuances desses movimentos.

Além disso, o grande esforço de entrelaçamento narrativo de dois contextos urbanos bastante distintos, Londres e Rio de Janeiro, não recebe a mesma atenção ao lidar com as assimetrias entre os campos médicos das duas cidades. Embora o fato de que existiam grandes diferenças entre os atores e instituiçóes londrinos e os cariocas seja presumível e esteja presente em pontos da obra, não chega a ser detalhado. Tal detalhamento fortaleceria o argumento da autora, bem como contribuiria para a análise acerca da constituição socioprofissional da medicina no Brasil.

Em outro movimento analítico, Myriam Bahia Lopes realiza com frequência uma diacronia entre a vacina antivariólica no século XIX e a imunologia na segunda 
metade do século XX. Ainda que o elemento diacrônico seja fundamental para pensar os ecos da história da vacina e da vacinação, é necessário observar que não somente os conhecimentos e práticas de prevenção mudaram entre o final do XVIII e o do XX, mas também os regimes de objetividade (Daston; Galison, 2007) na medicina. Ao falar sobre o (complexo) processo de incorporação de inovaçôes técnicas à prática médica, Bahia Lopes (2020: 188) afirma que "a história da técnica médica coloca os homens em uma relação de subordinação diante dos instrumentos que eles inventam e dos quais eles servem". Essa afirmação pode ser coerente para o século XIX, no contexto do que Daston e Galison (2007) chama de objetividade mecânica, segundo a qual a legitimidade do empreendimento científico está condicionada ao manejo de instrumentos pelos cientistas e na produção de inscrições através deles. Entretanto, pensando na diacronia com o fim do século XX - e o questionamento da autora sobre "quais são os fatores que empurram a pesquisa para além do ponto das dúvidas e incertezas" (Bahia Lopes, 2020: 190) -, refere-se a um regime de objetividade regulatória (Cambrosio et al., 2006), pautado na produção coletiva de evidências e na diminuição da autoridade do cientista individualmente.

Dessa forma, algumas consideraçóes gerais da autora quanto ao empreendimento técnico-científico e a relação da medicina com o conhecimento parecem não levar em consideração a historicidade e a dinamicidade da própria ciência. Esse é o caso quando a autora comenta que a história da vacina antivariólica "demonstra uma enorme dificuldade por parte de seus agentes em compreender a complexidade do percurso que vai do laboratório até a sociedade" (Bahia Lopes, 2020: 205). O que a própria análise da autora mostra é algo diferente, com atores mobilizando-se não somente para levar uma inovação do laboratório para a sociedade, mas também tentando mudar a ordem social através da técnica. A questão está exatamente nas formas como a sociedade responde aos cientistas e aos médicos e nas transformaçóes do próprio instrumento vacina.

Por último, gostaria apenas de pontuar uma importante discussão, também bastante atual, envolvendo a distinção entre vacina e vacinação. Insisto em pontuar a vacina como um instrumento a fim de diferenciá-la da vacinação, a estratégia de saúde pública/coletiva para controlar ou erradicar uma doença. Embora os sentidos de diferenciação entre a prática médica e a saúde pública sejam distintos no século XIX e no XX, é necessário demarcar que a história da técnica não pode se confundir 
com a da estratégia, a despeito dos entrelaçamentos. Essa percepção auxilia a compreensáo de aspectos mais simples, como o fato de a existência de uma vacina não significar a garantia de uma vacinação, mas também de questôes complexas, a exemplo da incorporação de inovaçôes técnicas de saúde por Estados nacionais.

\section{Considerações finais}

Em Corpos Inscritos, Myriam Bahia Lopes traz uma abordagem importante sobre os movimentos antivacinistas, atribuindo protagonismo dos grupos contrários à vacinação no próprio desenvolvimento da vacina antivariólica entre os séculos XIX e XX. Permeado por diferentes temporalidades, o livro precisa ser lido tendo em conta seu contexto de produção e o de publicação, uma vez que oferece elementos para debates interessantes em ambos. Analisar o antivacinismo além da "vacinofobia", situando-o como um movimento social com pautas bem formuladas e internacionalizadas, é um aspecto que faz jus à história social e à história cultural em uma leitura crítica ao biopoder. O debate sobre as simetrias entre defensores e críticos da vacina e a historicidade da vacina como instrumento, monumento ou acontecimento, porém, segue em aberto.

\section{Referências}

BAHIA LOPES, Myriam. Corpos Inscritos: vacina e biopoder, Londres e Rio de Janeiro, 1840 e 1904.

BLORR, David. Conhecimento e imaginário social. São Paulo: Ed. Unesp, 2009.

CAMBROSIO, Alberto et al. Regulatory objectivity and the generation and management of evidence in medicine. Social Science \& Medicine, v. 63 (1), 2006, p. 189-199.

CERTEAU, Michel de. A Invenção do Cotidiano. Volume 1: Artes de Fazer. Petrópolis: Editora Vozes, 2012.

. História e Psicanálise: entre ciência e ficção. Belo Horizonte: Editora

Autêntica, 2011.

CLARKE, Adele; FUJIMURA, Joan. The right tools for the job: at work in Twentieth-Century Life Sciences. Princeton: Princeton University Press, 1992.

DASTON, Lorraine; GALISON, Peter. Objectivity. New York: Zone Books, 2007.

HUISMAN, Frank; WARNER, John Harley. "Medical Histories”. In: Locating Medical History: the stories and their meanings. Baltimore: John Hopkins University Press, 2006. p. 1-30. 
KOSELLECK, Reinhart. Estratos do tempo: estudos sobre história. Rio de Janeiro: Editora Contraponto, 2014.

. Futuro Passado: contribuiçâo à semântica dos tempos históricos. Rio de Janeiro: Editora Contraponto/PUC, 2006.

KRANTZ, Frederick (org.). A Outra História: ideologia e protesto popular nos séculos XVII a XIX. Rio de Janeiro: Jorge Zahar, 1990.

LATOUR, Bruno. Ciência em ação: como seguir cientistas e engenheiros sociedade afora. São Paulo: Editora Unesp, 2000.

LAW, John. "STS as method". In: FELT, Ulrike et al. The Handbook of Science and Technology Studies. Fourth Edition. Cambridge/London: The MIT Press, 2017, p. 31 - 57.

ORESKES, Naomi. Why Trust Science? Princeton: Princeton University Press, 2019.

RUNIA, Eelco. Moved by the past: discontinuity and historical mutation. Nova York: Columbia University Press, 2015.

SHAPIN, Steven; SCHAFFER, Simon. Leviathan and the Air-pump: Hobbes, Boyle, and the experimental life. Cambridge: Harvard University Press, 2011.

\section{Nota}

${ }^{1}$ Segundo Law (2017: 31. Tradução livre), a "ciência é poderosa, mas, na prática, o método científico é material e bagunçado". 